\title{
Fate of contaminants in Baltic Sea sediments: role of bioturbation and settling organic matter
}

\author{
Jenny E. Hedman ${ }^{1, *}$, Clare Bradshaw ${ }^{1,2}$, Maria H. Thorsson ${ }^{2}$, Michael Gilek ${ }^{2}$, \\ Jonas S. Gunnarsson ${ }^{1}$
}

${ }^{1}$ Department of Systems Ecology, Stockholm University, 10691 Stockholm, Sweden

${ }^{2}$ School of Life Sciences, Södertörn University College, 14189 Huddinge, Sweden

\begin{abstract}
This experimental study examined the interactive effects of bioturbation and settling organic matter (OM) on the fate (burial and remobilisation) of 2 surface-deposited contaminants in Baltic Sea sediment: the metal Cd and a hydrophobic organic pollutant, the flame retardant BDE-99. Three macrofaunal species with diverse feeding and bioturbation strategies were used: the amphipod Monoporeia affinis, the clam Macoma balthica and the polychaete Marenzelleria spp. Radiolabelled contaminants were added to the sediment surface in association with 3 different OM types: (1) phytoplankton, (2) terrestrial lignin and (3) Baltic sediment. Bioturbation by all species increased the retention of both contaminants in the sediment, most effectively $M$. affinis and $M$. balthica. A decoupled transport of Cd and BDE-99 by Marenzelleria was observed. Generally, Marenzelleria buried the highest amount of $\mathrm{Cd}$ into the sediment but also caused the highest remobilisation to the water, indicating an effective transport of (soluble) $\mathrm{Cd}$ over the sediment-water interface via bioirrigation. Lack of the highly hydrophobic and mainly particle-associated BDE-99 below the sediment surface suggests that Marenzelleria caused no significant particle mixing. The addition of various OM types significantly affected the distribution of $\mathrm{Cd}$, but not of BDE-99. There was an interactive effect between bioturbation (species) and OM type, generally showing an increased burial and release of $\mathrm{Cd}$ when associated with phytoplankton in the presence of Marenzelleria. Our results emphasise the importance of understanding the complex interactions between ecological (e.g. infaunal feeding and bioturbation activities) and physiochemical processes (contaminant speciation and sorption kinetics) when assessing the fate of contaminants in aquatic ecosystems.
\end{abstract}

KEY WORDS: Cadmium $\cdot$ BDE-99 $\cdot$ HOC $\cdot$ POP $\cdot$ Flame retardant $\cdot$ Marenzelleria spp. $\cdot$ Macoma balthica $\cdot$ Monoporeia affinis $\cdot$ Remobilisation

\section{INTRODUCTION}

A key process for the fate of many persistent organic pollutants (e.g. PCBs, dioxins) and metals (e.g. $\mathrm{Cd}, \mathrm{Pb}$ ) in aquatic ecosystems is their sorption to settling organic matter (OM) and subsequent deposition on and burial in sediments. Contaminants can be effectively incorporated into the sediment as a result of active bioturbation (i.e. sediment reworking) by benthic infauna (Gilbert et al. 1996, Magnusson et al. 2003). This can increase the retention of contaminants in the sediment and reduce their bioavailability, mak- ing the sediment an important sink. However, bioturbation can also lead to an increased mobilisation of sediment-associated contaminants (Ciarelli et al. 1999, Ciutat \& Boudou 2003).

The specific effect of macrofaunal bioturbation on contaminant fate in sediments has been attributed to the organisms' mode of bioturbation, i.e. their feeding and burrowing strategies and intensity (Schaffner et al. 1997, Petersen et al. 1998, Christensen et al. 2002, Banta \& Andersen 2003). Random mixing (biodiffusion) and advective transport of particles within the sediment by infauna is especially important for the 
cycling of sediment-associated organic contaminants and metals (Ferro et al. 2003, Caradec et al. 2004). Bioirrigation, on the other hand, increases the flux of solutes, i.e. dissolved compounds in the pore water and over the sediment-water interface (Aller \& Aller 1998). The partitioning of a contaminant between the solid and water phase in sediments depends on the contaminant's inherent properties and the biogeochemical state of the sediment. Hydrophobic organic contaminants (HOCs) preferentially adsorb to particulate OM in sediments, and their distribution between phases generally can be calculated based on the physiochemical properties of the compound, such as water solubility and lipophilicity, and the amount of OM in the sediment (Schwarzenbach et al. 2003). The partitioning of metals is strongly affected by the sediment chemical environment, such as $\mathrm{pH}$, redox conditions and the presence of other chemical species (Chapman et al. 1998). Under oxic conditions, many metal contaminants, e.g. $\mathrm{Cd}, \mathrm{Cu}$ and $\mathrm{Zn}$, partition to OM or inorganic fractions, such as clay particles and oxides/hydroxides, while the formation of less soluble metal sulphides dominates in anoxic sediments (Di Toro et al. 1990, Audry et al. 2006). Bioturbation can significantly affect the biogeochemical properties of the sediment, e.g. oxygenation, OM degradation and microbial activities (Aller 1988, Kristensen et al. 1992), and thereby also change the partitioning of contaminants.

Settling OM is the main food source for deposit-feeding infauna (Graf 1992). Typically, the supply of OM to benthic communities varies spatially and temporally, both in terms of quantity and quality. The 'quality' of OM can be defined in different ways and relates here to its nutritional value to benthic organisms and susceptibility to biodegradation (Gunnarsson et al. 1999a). Labile OM, e.g. phytoplankton, is highly nutritious and readily biodegraded, whereas refractory OM usually contains more low-quality structural elements, such as lignins and cellulose, and is more resistant to degradation. A positive relationship between bioturbation intensity and food availability has been found in several studies (Jumars \& Wheatcroft 1989, Maire et al. 2006), and a more rapid burial of fresh particulate OM compared to older, more refractory OM has been suggested as a theory of 'age-dependent' mixing (Smith et al. 1993). Another aspect of OM 'quality' is the importance of its chemical composition in relation to contaminant sorption capacity. Generally, it is suggested that contaminants are more strongly associated with older refractory OM than with fresh labile OM (Lueking et al. 2000). OM composition may therefore influence the partitioning and distribution of contaminants in sediments directly due to their various sorption capacities, and indirectly by acting on the feeding and bioturbation activities of animals.
We investigated how the fate of surface-deposited contaminants was affected by: (1) bioturbation by benthic invertebrates with diverse feeding and bioturbation strategies, and (2) settling OM from different sources and of different nutritional qualities. Three common infaunal Baltic Sea species were used: the amphipod Monoporeia affinis, the clam Macoma balthica and the spionid polychaete Marenzelleria spp. The amphipod and the clam are mainly biodiffusors, mixing particles in the upper $5 \mathrm{~cm}$ of the sediment, while the polychaete creates semi-permanent burrows down to about $30 \mathrm{~cm}$. We used 2 model compounds with different chemical characteristics: the metal cadmium $(\mathrm{Cd})$ and a hydrophobic organic contaminant, the flame-retardant BDE-99. $\mathrm{Cd}$ is a common contaminant in aquatic environments, including the Baltic Sea (HELCOM 2003). During oxidising conditions, $\mathrm{Cd}$ can be mobilised to the sediment interstitial water due to the formation of free metal ions and complexation with soluble organic and inorganic ligands, while in reduced sediment, Cd forms insoluble sulphide precipitates (Di Toro et al. 1990). Polybrominated diphenyl ethers (PBDEs) are a group of persistent organic pollutants with high hydrophobicity (log $K_{\mathrm{OW}}$ values 4 to 10), high sorption affinity to particles and a tendency to accumulate in sediments and biota (de Wit 2002). Chemically, PBDEs resemble other HOCs, e.g. PCBs, but our knowledge of their environmental fate and effects is in comparison very limited. BDE-99 is one of the most commonly encountered PBDE congeners in environmental samples (de Wit 2002).

Both contaminants were added to the sediment surface associated with the different OM types. Our main hypotheses were that the redistribution of $\mathrm{Cd}$ and BDE-99 would be species-specific, and that the input of settling OM with a high nutritional quality would stimulate infaunal feeding and bioturbation activities, thereby increasing the overall redistribution of the associated contaminants.

\section{MATERIALS AND METHODS}

Experimental design. The experiment was performed using a 2-factorial design with animal and OM as fixed factors. The animal factor had 4 levels (3 different animal species and a control without animals). The OM factor had 3 levels (3 types of OM). Each treatment had 3 replicate sediment cores. Dependent variables were the measured activities of the 2 contaminants $\mathrm{Cd}$ and BDE-99. The distributions of the 2 contaminants within the same core were analysed in 2 separate 2 -way analyses of variance (ANOVA), i.e. no statistical comparisons were done between Cd and BDE-99.

Field sampling and preparation of microcosm systems. Surface sediment (top $5 \mathrm{~cm}$ ) was collected in 
December from a depth of $45 \mathrm{~m}$ using a benthic sledge at Asenskallen $\left(58^{\circ} 46.5^{\prime} \mathrm{N}, 17^{\circ} 41.4^{\prime} \mathrm{E}\right)$ near the Askö Marine Laboratory, NW Baltic Proper. The fresh sediment was sieved immediately, without the addition of extra water, through a $1 \mathrm{~mm}$ sieve into $30 \mathrm{l}$ buckets and was then left with overlying aerated brackish water in a thermoconstant room at $4^{\circ} \mathrm{C}$ for 2 mo to settle and reestablish a natural sediment geochemical profile. All brackish water (6.4 to $6.7 \mathrm{psu}$ ) used in the experiment was collected at the Askö Marine Laboratory at $15 \mathrm{~m}$ depth and filtered through a $0.8 \mathrm{~mm}$ sand filter.

Three infaunal species were collected in January. The bivalve Macoma balthica and the amphipod Monoporeia affinis were collected in Hållsviken $\left(58^{\circ} 49.7^{\prime} \mathrm{N}\right.$, $\left.17^{\circ} 32.3^{\prime} \mathrm{E}\right)$ at $33 \mathrm{~m}$ depth. Polychaete Marenzelleria spp. were sieved out of sandy sediment collected at $1 \mathrm{~m}$ water depth off the island of Mörkö $\left(59^{\circ} 2.29^{\prime} \mathrm{N}\right.$, $\left.17^{\circ} 41.45^{\prime} \mathrm{E}\right)$. Recent genetic studies have suggested that there are at least 3 different species of the genus Marenzelleria in the Baltic Sea (Bastrop \& Blank 2006). They are morphologically similar, and the individuals used in this experiment were not identified to species and are therefore hereafter referred to only by the genus name. All species were held for several weeks at field temperature $\left(4^{\circ} \mathrm{C}\right)$ in separate $30 \mathrm{l}$ aquaria containing sediment and water from the field area. The overlying water was continuously aerated and changed approximately every other week until the start of the experiment.

Kajak tube cores (inner diameter $8 \mathrm{~cm}$, height $50 \mathrm{~cm}$ ) were pushed by hand into the collected sediment, with care taken to avoid the formation of air bubbles, and then filled to the top with brackish water. They were sealed with a rubber stopper at the top and pulled out of the bucket, retaining the sediment by vacuum in the tube core. Another cork stopper was placed at the bottom of the cores, which were subsequently placed in a thermoconstant room at $4^{\circ} \mathrm{C}$. The cores had a sediment column of ca. $30 \mathrm{~cm}$ height $(1500 \mathrm{ml})$ and a water column of ca. $17 \mathrm{~cm}(850 \mathrm{ml})$. Aeration was provided by gently bubbling air through glass tubes inserted through the top stoppers. The stoppers had another hole to let air out and a third hole connected to silicone tubing for the collection of water samples. The cores were kept in a thermoconstant room for $5 \mathrm{wk}$ before the addition of animals and the start of the experiment.

The number of animals added to the cores corresponded to average field densities common in the Baltic Sea (Table 1); therefore, all results in this experiment relate to the natural field density of each species. After addition to the core tubes, most of the animals buried into the sediment within $5 \mathrm{~min}$. Animals that had not burrowed after $24 \mathrm{~h}$ (2 Marenzelleria and 4 Macoma balthica) were replaced by new animals. The cores were placed randomly in the thermoconstant room, which was held at a constant temperature of $4^{\circ} \mathrm{C}$
Table 1. Number of animals and biomass added to the sediment cores

\begin{tabular}{|c|c|c|c|c|}
\hline & $\begin{array}{l}\text { No. of an } \\
\text { Per core }\end{array}$ & $\begin{array}{l}\text { imals } \\
\text { Per } \mathrm{m}^{2}\end{array}$ & \multicolumn{2}{|c|}{$\begin{array}{l}\text { Average total bio- } \\
\text { mass per core } \\
\text { (g wet wt) ( } g \text { dry wt) }\end{array}$} \\
\hline Monoporeia affinis $^{\mathrm{a}}$ & 15 & 3000 & 0.1 & 0.011 \\
\hline Macoma balthica ${ }^{\mathrm{b}}$ & 5 & 1000 & 4.7 & $0.236^{\mathrm{b}}$ \\
\hline Marenzelleria spp. ${ }^{\mathrm{C}}$ & 7 & 1400 & 1.0 & 0.072 \\
\hline Control & - & - & - & - \\
\hline $\begin{array}{l}\text { andividuals }>1 \mathrm{~mm} \mathrm{l} \\
{ }^{\mathrm{b}} \text { Shell size ca. } 20 \mathrm{~mm} \\
\text { Individuals ca. } 5 \mathrm{~cm}\end{array}$ & $\begin{array}{l}\text { long, no gl } \\
\text { n. Shell-fre } \\
\text { long with }\end{array}$ & $\begin{array}{l}\text { ravid fen } \\
\text { ee dry w } \\
\text { visible }\end{array}$ & $\begin{array}{l}\text { males } \\
\text { reight } \\
\text { feeding }\end{array}$ & \\
\hline
\end{tabular}

and a dark:light cycle with green light to mimic field conditions. The animals were allowed to acclimatise to the experimental conditions for $1 \mathrm{wk}$ before the addition of spiked OM (see below).

Contaminants and organic material. Two radiolabelled contaminants were used in the experiment. ${ }^{14}$ C-labelled BDE-99 (2, 2', 4, 4', 5-pentabromodiphenyl ether) dissolved in acetone (synthesised by the Department of Environmental Chemistry, Stockholm Univer-

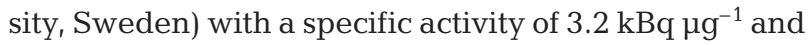
$\log K_{\text {OW }}$ of 7.13 (Tittlemier et al. 2002). ${ }^{109} \mathrm{CdCl}_{2}$ in $0.1 \mathrm{M}$

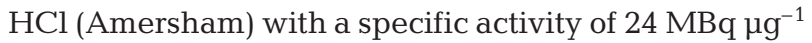
$\mathrm{Cd}$. This activity and all following ${ }^{109} \mathrm{Cd}$ activities were corrected for radioactive decay to 1 March 2004.

Three different types of OM were used: (1) microalgae, i.e. green flagellate algae Tetraselmis spp. (Reed Mariculture, San Jose, CA, USA); (2) terrestrial wood fibres of lignin (Curan 100, Holmen paper AB, Sweden); and (3) surface sediment (i.e. same as the sediment used in the cores). The different types represented a high (Tetraselmis spp.), low (lignin) and medium (sediment) quality OM source to the benthic invertebrates. The quality is here referred to as the nutritious value of the OM source, defined as the relative amount of total nitrogen (TN) to total carbon (TC) in the OM (Gunnarsson et al. 1999a,b). Chemical characteristics used to define the quality of the 3 OM sources are presented in Table 2 . Tetraselmis spp. have a high content of fatty acids and

Table 2. Properties of the OM additions and the amount of TOC added to each core

\begin{tabular}{|c|c|c|c|c|c|c|}
\hline & \multirow[t]{2}{*}{$\begin{array}{l}\text { Nutritional } \\
\text { quality }^{\mathrm{a}}\end{array}$} & \multirow[t]{2}{*}{$\begin{array}{l}\mathrm{TN} \\
(\%)\end{array}$} & \multirow[t]{2}{*}{$\begin{array}{l}\mathrm{TC} \\
(\%)\end{array}$} & \multirow[t]{2}{*}{$\begin{array}{l}\text { TOC } \\
(\%)\end{array}$} & \multicolumn{2}{|c|}{$\begin{array}{c}\text { TOC added } \\
\text { (g dry wt) }\end{array}$} \\
\hline & & & & & Per core & Per $\mathrm{m}^{2}$ \\
\hline Algae & High & 5.02 & 40.2 & 32.2 & 0.0486 & 9.7 \\
\hline Lignin & Low & 0.11 & 66.4 & 62.8 & 0.0481 & 9.6 \\
\hline Sediment ${ }^{\mathrm{b}}$ & Medium & 0.27 & 1.77 & 1.37 & 0.0483 & 9.7 \\
\hline \multicolumn{7}{|c|}{ aFrom Gunnarsson et al. (1999a,b) } \\
\hline${ }^{\mathrm{b}}$ Same as $\mathrm{t}$ & the sediment & it in th & (1) & & & \\
\hline
\end{tabular}


amino acids and are therefore considered a labile OM source and palatable food source to marine detrivores, while lignins consist of unpalatable refractory aromatic polymers (Gunnarsson et al. 1999a).

Preparation of the organic material, spiking and addition to the cores. A concentrate of thawed Tetraselmis algae was washed and centrifuged 5 times for $20 \mathrm{~min}$ at $2700 \times g$ in brackish water to remove as much dissolved $\mathrm{OM}$ as possible, leaving a suspension of intact non-living algal cells. Dry powdered lignin was made into a suspension by adding brackish water and shaking vigorously. The suspension was then centrifuged for $15 \mathrm{~min}$ at $2700 \times g$ and the dissolved OM and very fine particles removed with the supernatant. The sediment was thoroughly mixed before being used as the third OM source. An amount corresponding to a final nominal enrichment of $0.05 \mathrm{~g}$ dry weight (dry wt) organic carbon (OC) per core, or ca. $10 \mathrm{~g}$ dry wt OC $\mathrm{m}^{-2}$, was prepared from each OM source, based on their total OC (TOC) content (Table 2). The amount of OC $\left(10 \mathrm{~g} \mathrm{OC} \mathrm{m}^{-2}\right)$ was chosen to provide an organic enrichment equivalent to the settling of OM during a spring bloom in the Baltic Sea (Larsson et al. 1986).

Radiolabelled BDE $\left({ }^{14} \mathrm{C}-\mathrm{BDE}-99\right)$ and the radioisotope ${ }^{109} \mathrm{Cd}$ were combined with each of the OM sources to produce a spiked stock. The amounts of ${ }^{14} \mathrm{C}-\mathrm{BDE}$ and ${ }^{109} \mathrm{Cd}$ were calculated to give a final nominal activity of $27 \mathrm{kBq}$ and $118 \mathrm{kBq}$ core $^{-1}$, respectively. Nominal activities were chosen to be detectable at the end of the experiment following bioturbation and mixing into the sediment, uptake by the animals and radioactive decay. These concentrations (equivalent to $8.44 \mu \mathrm{g}$ BDE core $^{-1}$ and $0.0049 \mu \mathrm{g} \mathrm{Cd}$ core $^{-1}$ ) were also below reported toxic concentrations for similar species. For example, LC50s for Cd are in the range of $31 \mathrm{\mu g} \mathrm{l}^{-1}$ (Voyer \& Modica 1990) to $1.7 \mathrm{mg} \mathrm{l}^{-1}$ (DeWitt et al. 1999), and for various BDE congeners they are $108 \mathrm{\mu g} \mathrm{l}^{-1}$ to $2.4 \mathrm{mg} \mathrm{l}^{-1}$ (Wollenberger et al. 2005). First ${ }^{14} \mathrm{C}-\mathrm{BDE}$, then the $\mathrm{OM}$ source, and lastly the ${ }^{109} \mathrm{CdCl}_{2}$ solution were added to Erlen flasks, which were then sealed with Parafilm and placed on magnetic stirrers at $4^{\circ} \mathrm{C}$ for $7 \mathrm{~d}$ to ensure a homogenous spiking of the organic material. The spiked OM was then divided into aliquots containing equal amounts of $\mathrm{OC}$ (and ${ }^{109} \mathrm{Cd}$ and ${ }^{14} \mathrm{C}$-BDE) for addition to the cores.

The spiked organic materials were added to the overlying water of the cores through a glass funnel, with its tip held close to the sediment surface, and allowed to settle for $12 \mathrm{~h}$ without aeration. After this, the overlying water was siphoned off carefully to minimise resuspension and replaced with new brackish water. This was done to remove remaining spiked OM in the water, as the focus of the experiment was to examine contaminant redistribution from the sediment surface, and to be able to measure the remobilisation of settled contaminants back into the water column. A $10 \mathrm{ml}$ water sample was taken from the removed water to estimate the loss of ${ }^{14} \mathrm{C}$-BDE and ${ }^{109} \mathrm{Cd}$ with the water change. The cores were then sealed with corks and aeration was switched on. Salinity was maintained between 6.4 and 6.7 psu throughout the experiment. The experiment was run for $34 \mathrm{~d}$.

Sample collection and preparation. At the end of the experiment, the cores were processed in random order. First, a $20 \mathrm{ml}$ sample from the overlying water column was taken. The remaining water was removed and mixed, and a volume of 20 to $120 \mathrm{ml}$ of water was filtered through pre-combusted $\left(550^{\circ} \mathrm{C}\right)$ and preweighed GF/F filters in order to measure suspended particles $(>0.7 \mu \mathrm{m})$ and radioactivity associated with suspended particles. The filtered volume depended on the amount of suspended matter in the water and how fast the filters became clogged. The filters were dried for $24 \mathrm{~h}$ at $60^{\circ} \mathrm{C}$ and weighed again to obtain the dry weight of the suspended particles. Water samples were kept in $20 \mathrm{ml}$ glass scintillation vials at $4^{\circ} \mathrm{C}$ until analysed.

The sediment in the cores were pushed up from the bottom using a plunger and a cork that was tightly fit within the core, and sliced into $1 \mathrm{~cm}$ slices from 0 to $5 \mathrm{~cm}$, thereafter at $6-7,8-9$ and $14-15 \mathrm{~cm}$, and in the Marenzelleria and control treatments also at $20-21 \mathrm{~cm}$. Redox potential was first measured at the sediment surface and then immediately after slicing at the fresh sediment surface in each slice using a platinum electrode with a calomel reference electrode (Beckman Coulter) connected to a radiometer (Orion, pH meter) (Bogander 1976). In each slice, the most peripheral few $\mathrm{mm}$ of sediment were discarded to avoid edge effects, animals were gently picked out using forceps and detailed sediment samples from burrow linings were collected when possible. The remaining wet bulk sediment, approximately $40 \mathrm{ml}$, was thoroughly mixed and kept at $4^{\circ} \mathrm{C}$ until analysis. Ten $\mathrm{ml}$ of wet bulk sediment from each slice were put in $60 \mathrm{ml}$ flat-bottomed containers for gamma analysis $\left(\mathrm{Cd}^{109}\right)$, and a subsample was taken for scintillation counting $\left({ }^{14} \mathrm{C}-\mathrm{BDE}\right)$. The bulk sediment subsamples and detailed sediment samples of burrow linings were dried for $24 \mathrm{~h}$ at $60^{\circ} \mathrm{C}$ to obtain their dry wt.

Chemical analyses and radioactivity measurements. TC and TN content of the sediment and the OM sources were measured using oven-dried samples on a Leco CHNS 932 analyser. TOC was determined after acidification with $\mathrm{HCl}$ (Hedges \& Stern 1983).

All samples were first analysed for ${ }^{109} \mathrm{Cd}$ using gamma spectrometry (Canberra GC2020 [GA1] and Ortec GEM HPGe-detectors), which detects only the gamma-emitting ${ }^{109} \mathrm{Cd}$, and then for total radioactive 
decay (combined ${ }^{109} \mathrm{Cd}$ and ${ }^{14} \mathrm{C}$ ) using liquid scintillation counting (LKB Wallac Rackbeta 1214). The same samples were processed for gamma and scintillation counting, except for the bulk sediment samples, for which the sample sizes had to be different for the 2 machines. Radioactivity measurements were corrected for different efficiencies, background and decay (in the case of ${ }^{109} \mathrm{Cd}$ ), and the ${ }^{109} \mathrm{Cd}$ activities were then subtracted from the total activities to provide ${ }^{14} \mathrm{C}-\mathrm{BDE}$ activities as described below.

For gamma analysis, sample geometry, counting efficiency and background radiation were corrected for, using matching standards with a known ${ }^{109} \mathrm{Cd}$ activity. Samples were run until the error of the measurement was less than $10 \%$ (between $10 \mathrm{~min}$ and $4 \mathrm{~h}$ depending on the activity). Counts were adjusted for radioactive decay to the date of subsequent scintillation counting and normalised to $\mathrm{g}$ dry wt (sediment) or ml (water samples).

Twenty-four hours before scintillation counting, $10 \mathrm{ml}$ Hionic-Fluor (Perkin Elmer Life and Analytical Sciences) were added to all sediment samples and $10 \mathrm{ml}$ Lumagel Safe (Lumac LSC) were added to all water samples. Detection efficiencies for both ${ }^{109} \mathrm{Cd}$ and ${ }^{14} \mathrm{C}$-BDE were calculated from equations derived from a series of standards with known activity. These standards represented all sample types so that the resulting equations covered the range of sample colours and colour quenching was taken into account. The 2 isotopes did not affect each others' detection efficiencies.

The amount of ${ }^{109} \mathrm{Cd}$ present in the scintillation sample was calculated using the activity per $g$ dry wt obtained from the gamma spectrometer, the efficiency equation for the scintillation machine and the weight of the sample. This was then subtracted from the total scintillation counts to obtain the amount of ${ }^{14} \mathrm{C}$.

Calculations and statistics. Downward burial of ${ }^{109} \mathrm{Cd}$ and ${ }^{14} \mathrm{C}$-BDE was quantified as follows. The measured activity per $\mathrm{g}$ dry wt in each cm-thick sediment slice was multiplied by the total dry wt of that slice. The total radioactivity in the bulk sediment of each core was calculated as the sum of the activities in the top 5 sediment slices ( 0 to $5 \mathrm{~cm}$ ), since no activity was detected in the bulk sediment below $5 \mathrm{~cm}$. Sediment profiles are thus based on the percentage of the total activity in the sediment at each $1 \mathrm{~cm}$ depth interval. The value '\% buried' was also calculated as the percentage activity found below $1 \mathrm{~cm}$ sediment depth. Mean depth was calculated by multiplying the percentage in each slice by the median depth of that slice (i.e. $0.5,1.5,2.5,3.5,4.5 \mathrm{~cm}$ ) and then adding together the products of all slices in each core. The percentage of particle-associated Cd and BDE-99 in the overlying water was calculated by dividing the activity measured on the filters, i.e. activity on the filter per volume filtrated water $\left(\mathrm{Bq} \mathrm{ml}^{-1}\right)$, by the activity measured in the whole water sample, i.e. both dissolved and particle-associated (Bq ml-1).

Statistical comparisons between treatments were tested by using a 2-factor ANOVA ( $<<0.05)$ followed by post-hoc multiple comparisons using the StudentNewman-Keuls (SNK) test to test for differences among treatments (within main effects). Data were log transformed, if necessary, to meet the assumptions of homogeneity of variances, evaluated using Cochran's C-test.

\section{RESULTS}

\section{Animal activity and recovery}

The cores were visually inspected on a daily basis. Amphipods were frequently observed swimming in the water column during the entire experimental period (34 d). Faecal pellets were continuously renewed at the sediment surface in cores with Macoma balthica and Marenzelleria, indicating continuous feeding and burrowing activity throughout the experiment. Polychaete burrows were observed from the side of the core down to $15 \mathrm{~cm}$ depth with a clear oxidised zone around the burrow linings.

All added individuals of Macoma balthica were recovered alive at the end of the experiment (100\% survival). Thirty-eight percent of the Marenzelleria were found whole and alive. Many of the worms were cut during the slicing of the cores, and when all pieces were included, close to $100 \%$ of the Marenzelleria were recovered. The recovery of Monoporeia affinis was $42 \%$ ( $52 \%$ when including dead individuals). The low recovery of amphipods was at least partly due to the difficulty of finding them without sieving the sediment and not due to high mortality (the sediment could not be sieved as it was needed intact for radioactivity analyses).

\section{Sediment characteristics and radioactivity measurements}

Sediment geochemistry and radioactivity data measured in the sediment at the end of the experiment are summarised in Table 3 . TOC content in the top $1 \mathrm{~cm}$ of sediment ranged between 1.5 and $1.9 \%$ among treatments. Water content ranged between $66 \%$ in the top sediment with Monoporeia affinis and $58 \%$ in the control cores. The redox potential discontinuity (RPD) layer, here denoting a sharp gradient in redox potential, was generally observed deeper in the sediment 
Table 3. Sediment geochemistry and radioactivity measured in the top $1 \mathrm{~cm}$ at the end of the experiment (34 d). The redox potential discontinuity (RPD) layer indicates the depth of a sharp gradient in the redox potential. TOC: total organic carbon, Control: no added macrofauna. Values are mean $\pm \mathrm{SD}, \mathrm{n}=3$

\begin{tabular}{|c|c|c|c|c|c|}
\hline & $\begin{array}{c}\text { TOC } \\
(\%)\end{array}$ & $\begin{array}{c}\text { Water } \\
\text { content }^{\mathrm{a}} \\
(\%)\end{array}$ & $\begin{array}{l}\text { RPD } \\
(\mathrm{cm})\end{array}$ & $\begin{array}{l}{ }^{109} \mathrm{Cd} \\
\quad(\mathrm{kBq} \mathrm{c}\end{array}$ & $\begin{array}{l}{ }^{14} \mathrm{C}-\mathrm{BDE} \\
\text { dry } \mathrm{wt}^{-1} \text { ) }\end{array}$ \\
\hline \multicolumn{6}{|c|}{ Monoporeia affinis } \\
\hline Algae & 1.90 & 66 & $2-3$ & $2.8 \pm 0.5$ & $1.0 \pm 0.1$ \\
\hline Lignin & 1.77 & 66 & $2-3$ & $2.7 \pm 0.4$ & $0.7 \pm 0.1$ \\
\hline Sediment & 1.77 & 66 & $3-4$ & $4.8 \pm 0.3$ & $1.2 \pm 0.0^{\mathrm{b}}$ \\
\hline \multicolumn{6}{|c|}{ Macoma balthica } \\
\hline Algae & 1.67 & 61 & $4-6$ & $1.7 \pm 0.2$ & $0.6 \pm 0.2$ \\
\hline Lignin & 1.48 & 61 & $4-6$ & $1.4 \pm 0.7$ & $0.4 \pm 0.2$ \\
\hline Sediment & 1.48 & 61 & $4-6$ & $2.6 \pm 0.3$ & $0.6 \pm 0.3$ \\
\hline \multicolumn{6}{|c|}{ Marenzelleria spp. } \\
\hline Algae & 1.50 & 59 & $4-6$ & $1.1 \pm 0.3$ & $0.5 \pm 0.2^{\mathrm{b}}$ \\
\hline Lignin & 1.74 & 59 & $6-8$ & $2.0 \pm 0.7$ & $0.5 \pm 0.2^{\mathrm{b}}$ \\
\hline Sediment & 1.59 & 59 & $4-6$ & $2.9 \pm 0.4$ & $1.2 \pm 0.4^{\mathrm{b}}$ \\
\hline \multicolumn{6}{|l|}{ Control } \\
\hline Algae & - & 58 & $3-4$ & $1.2 \pm 0.1$ & $1.0 \pm 0.2$ \\
\hline Lignin & - & 58 & $3-4$ & $0.8 \pm 0.1$ & $0.3 \pm 0.1^{\mathrm{b}}$ \\
\hline Sediment & - & 58 & $4-6$ & $2.3 \pm 0.2$ & $0.8 \pm 0.0^{\mathrm{b}}$ \\
\hline \multicolumn{6}{|c|}{ aAverage per animal treatment } \\
\hline
\end{tabular}

cores with Marenzelleria (between 4 and $8 \mathrm{~cm}$ depth) and Macoma balthica (4 to $6 \mathrm{~cm}$ ) than in the control cores $(3$ to $6 \mathrm{~cm})$. In cores with Monoporeia affinis, however, the RPD layer was closer to the sediment surface $(2$ to $4 \mathrm{~cm})$ than in the controls. Despite the poor precision of the measured RPD layer, which was due to the crude scale of slicing, the results gave a good indication of relative differences between animal treatments. No differences in RPD depth between OM treatments were observed. In general, the activity of both ${ }^{109} \mathrm{Cd}$ and ${ }^{14} \mathrm{C}$-BDE per $g$ dry wt sediment in the top $1 \mathrm{~cm}$ was higher in the cores treated with sediment than those with algae or lignin. This was probably caused by a higher loss of Cd and BDE-99 in these treatments following the initial water change (estimated loss: $33 \pm 8 \%$ and $43 \pm 11 \% \mathrm{Cd}$ and $39 \pm 25 \%$ and $51 \pm 25 \%$ BDE-99 for algae and lignin, respectively) compared to the sediment treatment ( $2 \pm 2 \%$ for $\mathrm{Cd}$ and $3 \pm 1 \%$ for BDE-99).

\section{Burial of Cd and BDE-99 into the sediment}

The 2 contaminants were affected differently by the presence of macrofauna and OM additions (Fig. 1). In general, a higher fraction of Cd than of BDE-99 was transported deeper into the sediment. No contami- nants were detected below $1 \mathrm{~cm}$ depth in the control cores, i.e. those without macrofauna.

There was a significant interaction effect between animal and OM treatments on the mean burial depth of Cd (ANOVA $\left.; F_{6,24}=5.64, \mathrm{p}<0.001\right)$. In the algae and lignin treatments, the general pattern was Marenzelleria > Macoma balthica > Monoporeia affinis > control (Fig. 2A). A post-hoc SNK test showed that the mean burial depth of Cd was significantly higher in cores with Marenzelleria compared to all other animal treatments (SNK $\mathrm{p}<0.05$ ). In addition, the mean burial depth in cores with $M$. balthica was significantly higher in the algae treatment than in the control. In the sediment treatment, however, only $M$. balthica had a higher mean burial depth of $\mathrm{Cd}$ than the control. Within animal treatments, there were no significant differences between OM additions with the exception of a higher mean burial depth of Cd by Marenzelleria in the algae treatment compared to sediment $\left(\mathrm{SNK}_{i} \mathrm{p}<\right.$ 0.001; Fig. 2A).

No interaction was observed in the mean burial depth of BDE-99 between animal and OM treatments, and there was no significant effect of OM type. However, there was a significant animal effect $\left(\right.$ ANOVA $_{i} F_{3,22}=$ 3.47, $\mathrm{p}<0.05)$. The general pattern was Macoma balthica $>$ Monoporeia affinis $>$ Marenzelleria $>$ control in all OM treatments (Fig. 2A). The mean burial depth of BDE99 was significantly higher in cores with $M$. balthica than with Marenzelleria and controls $\left(\mathrm{SNK}_{;} \mathrm{p}<0.05\right)$.

The amount (\%) of $\mathrm{Cd}$ and BDE-99 buried below $1 \mathrm{~cm}$ had the same pattern as the mean burial depths, and showed the same significant differences between treatments except for the amount of $\mathrm{Cd}$ buried below $1 \mathrm{~cm}$ by Macoma balthica in the algae treatment (SNK; $\mathrm{p}=0.058$; Fig. 2B).

\section{Enrichment of Cd and BDE-99 in macrofaunal burrows}

There was a clear enrichment of both $\mathrm{Cd}$ and BDE-99 in the burrow linings of Marenzelleria and Macoma balthica compared to the surrounding bulk sediment down to $5 \mathrm{~cm}$ depth. Although highly variable between and within replicates, the factor of enrichment (burrow sediment / bulk sediment) for both Cd and BDE-99 in Marenzelleria and M. balthica burrows ranged from 2 to 4 in the surface sediment $(0$ to $1 \mathrm{~cm})$ and from 10 to 60 in the 3 to $5 \mathrm{~cm}$ slices. There were no differences between animal or between OM treatments. Both Cd and BDE-99 were also detected in Marenzelleria burrows at all analysed depths down to $15 \mathrm{~cm}$. No distinct Monoporeia affinis burrows were visible and hence no samples were taken. 
Cd (\%)
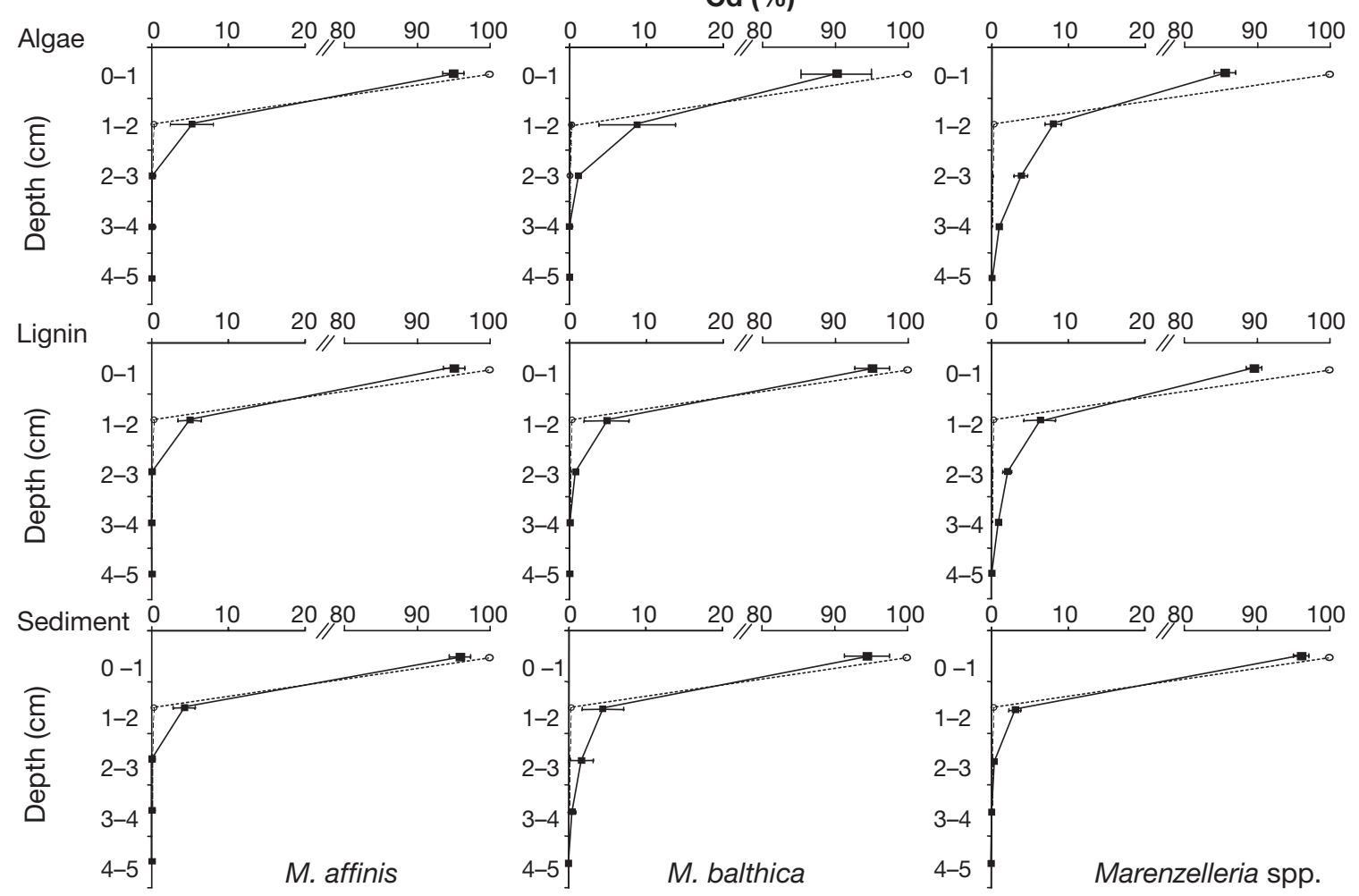

BDE-99 (\%)

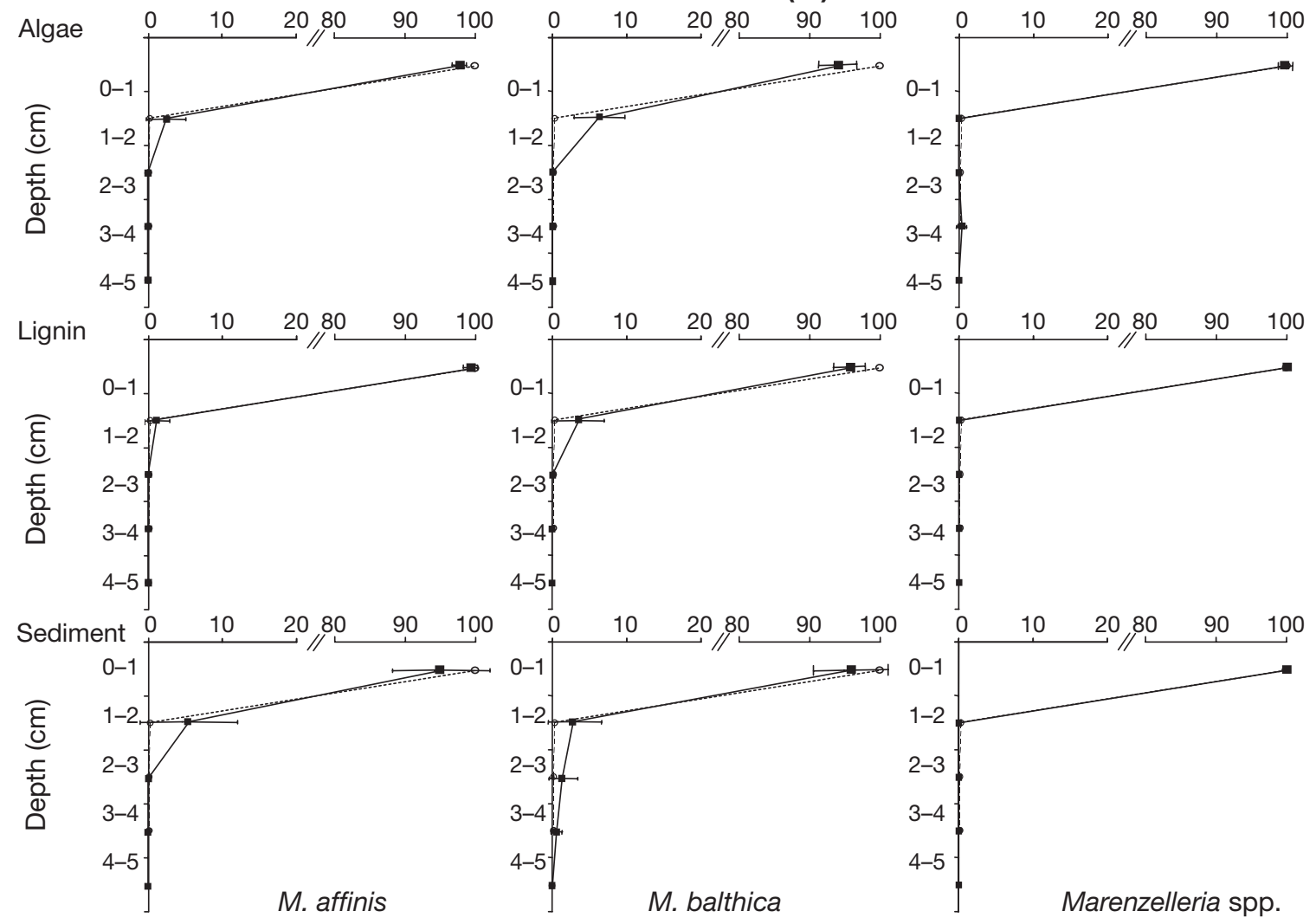

Fig. 1. Monoporeia affinis, Macoma balthica and Marenzelleria spp. Cd and BDE-99 depth profiles in sediment cores after $34 \mathrm{~d}$ of bioturbation (solid lines). Dashed lines are controls (no macrofauna). Cd or BDE-99 was added to the sediment surface associated with algae, lignin or sediment (rows) 

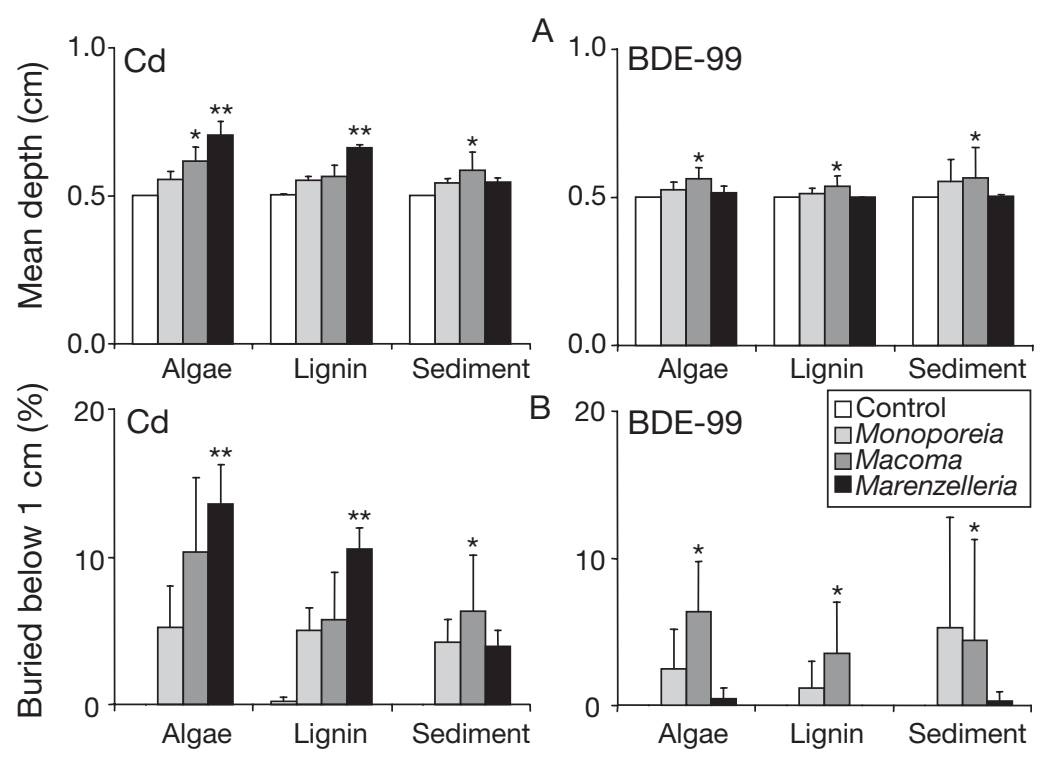

Fig. 2. Monoporeia affinis, Macoma balthica and Marenzelleria spp. (A) Mean burial depth and (B) percentage buried below $1 \mathrm{~cm}$ of Cd and BDE-99 in sediment microcosms with and without macrofauna (controls) after $34 \mathrm{~d}$. Contaminants were added associated with algae (Tetraselmis spp.), lignin or sediment. Cd: Significant interaction between animal and OM (ANOVA; mean burial depth $F_{6,24}=5.64, \mathrm{p}<0.001 ; \%$ buried $\left.F_{6,24}=2.93, \mathrm{p}<0.05\right) . M$. balthica $\left({ }^{*}\right)$ was significantly different from controls and Marenzelleria spp. $\left({ }^{* *}\right)$ from all other animals within each OM treatment ( $\left.\mathrm{SNK}_{i} \mathrm{p}<0.05\right)$. BDE-99: No interaction effect. $M$. balthica $\left(^{*}\right)$ significantly different from controls and Marenzelleria $\left(\mathrm{SNK}_{i} \mathrm{p}<0.05\right)$. Mean values, error bars denote $\mathrm{SD}, \mathrm{n}=3$

Table 4 . Radioactivity measured in the overlying water (unfiltered; $\mathrm{kBq}^{-1}$ ), suspended particles $\left(>0.7 \mu \mathrm{m} ; \mathrm{mg} \mathrm{l}^{-1}\right.$ ) and percentage particle-associated $\mathrm{Cd}$ and BDE-99 in the overlying water column at the end of the experiment (34 d). Control: no added macrofauna. All values are mean $\pm \mathrm{SD}, \mathrm{n}=3$

\begin{tabular}{|lccccc|}
\hline Treatment & $\begin{array}{r}{ }^{109} \mathrm{Cd} \\
\left(\mathrm{kBq} \mathrm{l}^{-1}\right)\end{array}$ & $\begin{array}{c}{ }^{14} \mathrm{C}-\mathrm{SDE} \\
\text { particles } \\
\left(\mathrm{mg} \mathrm{l}^{-1}\right)\end{array}$ & $\begin{array}{c}\text { Particle- } \\
\text { associated } \\
\mathrm{Cd}(\%)\end{array}$ & $\begin{array}{r}\text { Particle- } \\
\text { associated } \\
\text { BDE-99 }(\%)\end{array}$ \\
\hline $\begin{array}{l}\text { Monoporeia affinis } \\
\text { Algae }\end{array}$ & $1.0 \pm 0.4$ & $0.5 \pm 0.2$ & $158.3 \pm 91.7$ & $33 \pm 31$ & $63 \pm 20$ \\
Lignin & $0.6 \pm 0.2$ & $0.2 \pm 0.1$ & $121.1 \pm 76.4$ & $44 \pm 39$ & $91 \pm 31$ \\
Sediment & $0.6 \pm 0.4$ & $0.4 \pm 0.2$ & $137.5 \pm 79.6$ & $36 \pm 63$ & $57 \pm 34$ \\
Macoma balthica & & & & & \\
Algae & $0.7 \pm 0.3$ & $0.4 \pm 0.1$ & $19.3 \pm 17.2$ & $14 \pm 4$ & $13 \pm 4$ \\
Lignin & $0.8 \pm 0.4$ & $0.4 \pm 0.1$ & $17.5 \pm 1.9$ & $3 \pm 5$ & $10 \pm 5$ \\
Sediment & $1.1 \pm 0.4$ & $0.6 \pm 0.1$ & $14.3 \pm 0.5$ & $8 \pm 4$ & $9 \pm 2$ \\
Marenzelleria spp. & & & & \\
Algae & $2.8 \pm 0.5$ & $1.0 \pm 0.2$ & $33.5 \pm 8.9$ & $6 \pm 5$ & $28 \pm 9$ \\
Lignin & $3.1 \pm 1.4$ & $1.4 \pm 0.9$ & $29.9 \pm 3.3$ & $3 \pm 3$ & $9 \pm 5$ \\
Sediment & $2.6 \pm 0.4$ & $1.1 \pm 0.7$ & $27.6 \pm 9.8$ & $11 \pm 6$ & $19 \pm 18$ \\
Control & & & & & \\
Algae & $5.5 \pm 1.3$ & $2.6 \pm 0.2$ & - & $10 \pm 3$ & $15 \pm 3$ \\
Lignin & $2.9 \pm 1.3$ & $1.7 \pm 0.7$ & - & $2 \pm 2$ & $3 \pm 1$ \\
Sediment & $4.0 \pm 1.0$ & $2.3 \pm 0.3$ & - & $5 \pm 2$ & $4 \pm 1$ \\
\hline
\end{tabular}

\section{Remobilisation of Cd and BDE-99 to the overlying water}

The measured activity of $\mathrm{Cd}$ and BDE-99 $\left(\mathrm{Bq} \mathrm{ml}{ }^{-1}\right)$ in the overlying water at the end of the experiment is presented in Table 4 . To obtain a comparable net release of contaminants from the sediment, the measured activity in the overlying water $\left(\mathrm{Bq} \mathrm{ml} l^{-1}\right)$ was normalised to the concentration in the top $1 \mathrm{~cm}$ of sediment (Bq g dry $\mathrm{wt}^{-1}$ ). The general pattern of net release for both contaminants was control > Marenzelleria > Macoma balthica > Monoporeia affinis (Fig. 3).

The net release of $\mathrm{Cd}$ showed a significant interaction between animals and OM (ANOVA; $F_{6,24}=5.48, \mathrm{p}<$ 0.01 ). In the algae and lignin treatments, the net release of $\mathrm{Cd}$ in the control cores was significantly higher than when macrofauna were present $\left(\mathrm{SNK}_{i}\right.$ $\mathrm{p}<0.05$ ). In addition, in the algae treatment, the release of $\mathrm{Cd}$ caused by Marenzelleria was higher than that caused by $M$. balthica and $M$. affinis (SNK $\mathrm{p}<0.001)$. In the sediment treatment, there were no significant differences in the release of $\mathrm{Cd}$ to the water between any of the animal treatments. In the absence of macrofauna, the release of $\mathrm{Cd}$ to the water was significantly affected by the OM type (algae > lignin > sediment; Fig. 3). In cores with macrofauna, only the addition of algae to the cores with Marenzelleria increased the net release of $\mathrm{Cd}$ to the water compared to the sediment treatment (SNK; $\mathrm{p}<0.01$ ).

No interaction effects between animals and OM were observed for the release of BDE-99 to the water, and there were no differences between $\mathrm{OM}$ type. However, there was a significant difference between animals (ANOVA; $F_{3,22}=9.76, \mathrm{p}<0.001$ ), with a higher release in controls and Marenzelleria compared to Macoma balthica and Monoporeia affnis $\left(\mathrm{SNK}_{i} \mathrm{p}<0.05\right)$.

The amount of suspended particles in the water at the end of the experiment was highest in cores with Monoporeia affinis (up to $158.3 \pm 91.7 \mathrm{mg} \mathrm{l}^{-1}$ ) followed by Marenzelleria (33.5 \pm 

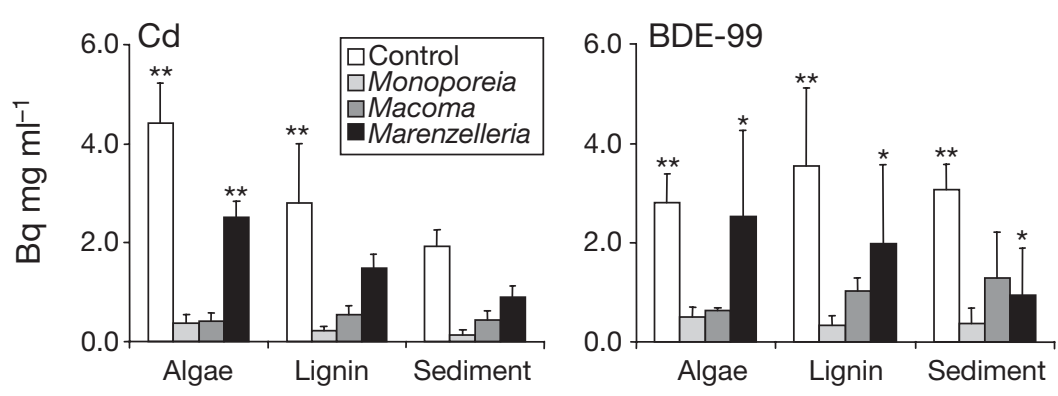

Fig. 3. Monoporeia affinis, Macoma balthica and Marenzelleria spp. Cd and BDE-99 in the overlying water $\left(\mathrm{Bq} \mathrm{ml}^{-1}\right)$ normalised to sediment concentration $\left(\mathrm{Bq} \mathrm{g} \mathrm{dw}^{-1}\right.$ ) in cores with or without macrofauna (control) after $34 \mathrm{~d}$. Contaminants were added associated with algae (Tetraselmis spp.), lignin or sediment. Cd: Significant interaction between animal and OM (ANOVA; $F_{6,24}=5.48, \mathrm{p}<$ 0.01). Controls and Marenzelleria spp. $\left(^{* *}\right)$ were significantly different from all other animal treatments (SNK; $\mathrm{p}<0.05)$. BDE-99: No interaction effect. Controls $\left({ }^{* *}\right)$ significantly different from all other animal treatments and Marenzelleria $\left({ }^{*}\right)$ from $M$. balthica and $M$. affinis $\left(\mathrm{SNK}_{i} \mathrm{p}<0.05\right)$. Mean values, error bars denote $\mathrm{SD}, \mathrm{n}=3$

$\left.8.9 \mathrm{mg} \mathrm{l}^{-1}\right)$ and Macoma balthica $\left(19.3 \pm 17.2 \mathrm{mg} \mathrm{l}^{-1}\right.$; Table 4). There were no observed differences between OM treatments. The percentage of particle-associated Cd (ANOVA $F_{3,24}=3.82, p<0.05$ ) and BDE-99 (ANOVA $F_{3,24}=39.6, \mathrm{p}<0.001$ ) in the overlying water differed significantly between animal treatments (Table 4). In cores with Monoporeia affinis, an average of $38 \pm 41 \%$ of the $\mathrm{Cd}$ and $70 \pm 30 \%$ of the BDE-99 in the overlying water was associated with suspended particles. This was a significantly higher ratio than in the other animal treatments for both Cd (average 6 to $8 \%$; $\mathrm{SNK}_{i} \mathrm{p}<0.05$ ) and BDE-99 (7 to $\left.19 \% ; \mathrm{SNK}_{i} \mathrm{p}<0.001\right)$.

\section{DISCUSSION}

Results from this experimental study show that the fate (i.e. sediment burial and remobilisation to water) of contaminants deposited on the sediment surface is strongly influenced by macrofaunal bioturbation, with clear differences between species, and that the association to settling OM of various origins was important. The simultaneous use of 2 contaminants with different chemical characteristics allowed a specific insight into the complex interactions between ecological (infaunal feeding and bioturbation activities) and physiochemical (contaminant speciation and sorption kinetics) processes affecting contaminant fate in a sediment ecosystem.

\section{Influence of bioturbation on the burial of Cd and BDE-99}

The polychaete Marenzelleria digs deep into the sediment, creating J-shaped un-branched burrows lined with a mucus layer (Zettler et al. 1995). In our study, the worms were observed down to $15 \mathrm{~cm}$, but they have been reported to create burrows down to $35 \mathrm{~cm}$ depth in natural environments (Zettler et al. 1995). They feed on detrital OM at the sediment-water interface and egest their faecal pellets at the sediment surface. Most burrowing polychaetes regularly ventilate their burrows with water from above the sediment surface to maintain a suitable living environment (Riisgard \& Larsen 2005). These bio-irrigation activities have been suggested to enhance the transport of soluble rather than particle-associated contaminants in the sediment (Banta \& Andersen 2003). There is little information available about bioirrigation by Marenzelleria. However, results from this study suggest an important transport of dissolved and/or apparently dissolved (e.g. dissolved OM-associated) compounds in their burrow structures and over the sediment-water interface.

Besides a clear enrichment of $\mathrm{Cd}$ in the Marenzelleria burrow walls as deep as $15 \mathrm{~cm}$, a relatively high amount of $\mathrm{Cd}$ was also detected in the bulk sediment to depths of $5 \mathrm{~cm}$. However, BDE-99 was only detected in the burrow walls but not in the bulk sediment. $\mathrm{Cd}$ primarily adsorbs to $\mathrm{OM}$ and to Fe and Mn oxides in sediments during oxidising conditions, with a small fraction present in the sediment interstitial water (Chapman et al. 1998). In a reducing environment, however, Cd can form sulphide complexes of very low solubility, also known as acid-volatile sulphides (AVS; Di Toro et al. 1990). The micro-zones created by infaunal burrow structures usually have strong redox gradients and high OM content (Aller 1988). Dissolved Cd transported into the sediment via bio-irrigation by Marenzelleria could be re-adsorbed at depth by metal oxides and OM in the oxidised mucus layer of polychaete burrows, and transit into the bulk sediment through molecular diffusion, where it could be precipitated due to anoxic conditions. For example, dissolved $\mathrm{Cd}$ transported from the overlying water into the burrows of the polychaete Nereis diversicolor was mainly adsorbed in the first 0 to $3 \mathrm{~mm}$ oxic layer but could penetrate into the bulk sediment up to $9 \mathrm{~mm}$ from the centre of the burrow (Petersen et al. 1998). BDE-99, on the other hand, is highly hydrophobic (log $K_{\mathrm{OW}} 7.13$ ) and generally sorbs strongly to particles and OM (de Wit 2002). The lack of BDE-99 below the sediment surface in the bulk sediment thus indicates that Marenzelleria did not cause any significant particle mixing in the upper sediment column. The local transport of par- 
ticle- and/or DOM-associated BDE-99 within the burrows could be a result of movement, burrow maintenance and downward transport of contaminated food particles. Similarly, other marine benthic invertebrates enrich HOCs, e.g. PCBs and PAHs, in their burrows (Gunnarsson et al. 1999a,b, Selck et al. 2005). BDE-99 transported into the burrow would rapidly associate with the organic-rich mucus layer and, in contrast to $\mathrm{Cd}$, not desorb and migrate into the bulk sediment.

The bivalve Macoma balthica lives a few centimetres down in the sediment, protruding its 2 siphons to the surface where it can switch between surface depositand suspension-feeding (Lin \& Hines 1994, Karlson et al. 2005). The clams mix particles from the surface into the sediment when they feed and move around, causing particles to fall into the space created around their shells. The burial of $\mathrm{Cd}$ and BDE-99 by M. balthica was probably mainly due to this type of passive particle displacement, indicated by the similar vertical distribution of both contaminants. Many bivalve species seem to have a limited influence on sediment-porewater exchange processes, since they feed and respire directly through their siphons (Mermillod-Blondin et al. 2005). Like Marenzelleria, M. balthica had elevated concentrations of both contaminants in its burrow lining compared to the bulk sediment. Although the burrow is not actively irrigated, it is likely that there is increased water circulation and hence oxygenation around the clam shell (Mermillod-Blondin et al. 2005, Michaud et al. 2005), as well as organic enrichment, resulting in an increased retention of both $\mathrm{Cd}$ and BDE-99 in the clam burrow walls.

The amphipod Monoporeia affinis is an active particle bioturbator in the upper centimetres of the sediment, causing extensive particle resuspension to the overlying water. The intense burrowing and ventilation activity by $M$. affinis and other similar amphipod species increases the porewater circulation, resulting in a higher sediment oxygen content and enhanced benthic nutrient fluxes over the sediment-water surface (Karlson et al. 2005, Riisgard \& Larsen 2005). The amphipods did not induce a transport of either $\mathrm{Cd}$ or BDE-99 below their depth of active burrowing $(2 \mathrm{~cm})$. It could have been expected that $M$. affinis, in addition to the downward mixing of particle-associated contaminants, would stimulate a transport of dissolved compounds, in this study primarily $\mathrm{Cd}$, below the zone of bioturbation due to a generally increased porewater flux in the upper sediment. However, no such transport of Cd was observed here. This could be due to a physical barrier created by the dense network of amphipod burrows hindering the molecular diffusion of $\mathrm{Cd}$ deeper into the sediment, as suggested by Petersen et al. (1998) in a similar study with the amphipod Corophium volutator. In our study, the RPD layer was measured just under the bioturbated layer, indicating no increase in porewater flux below the zone of bioturbation.

\section{Remobilisation to water}

Bioturbation by all species in this experiment significantly increased the retention of both Cd and BDE-99 in the sediment. The higher remobilisation of contaminants to the water in the control cores (no macrofauna present) was likely due to the fact that no $\mathrm{Cd}$ or BDE-99 had been buried in the sediment, i.e. all contaminants remained at the sediment surface and were available for desorption to the overlying water.

The same argument can be made for the relatively high release of BDE-99 in cores with Marenzelleria (no burial), but not for the remobilisation of $\mathrm{Cd}$, which was more effectively buried into the sediment by the polychaete than by the other species. Schaffner et al. (1997) found a relationship between the hydrophobicity of PAHs and PCBs and their fate in bioturbated sediments. The most hydrophilic compounds had the highest mean burial depths but they also had the highest loss rates from the sediments, probably due to a more effective macrofaunal transport of solutes than of particles. This is in agreement with the decoupled transport of $\mathrm{Cd}$ and BDE-99 in this study considering that even a small increase in redox potential can result in enhanced levels of dissolved $\mathrm{Cd}$ in the porewater and flux to the overlying water (Peterson et al. 1996, Riedel et al. 1999). Marenzelleria viridis increases the transport of oxygen over the sediment-water interface (Karlson et al. 2005), and the RPD layer in our study was generally extended deeper in cores with Marenzelleria than in controls.

Concentrations of both $\mathrm{Cd}$ and BDE-99 were very low in the overlying water in Macoma balthica and Monoporeia affinis cores. The clams caused little particle resuspension. This and the lack of active bioirrigation are the most likely reasons for the low release of contaminants to the water. However, the clams' constant pumping of water over the gills for respiration could also effectively filter out both suspended particles and contaminants present in the water. In the field, bivalves can significantly influence contaminant dynamics by transporting contaminants from the water column to the sediment through biodeposition of faeces and pseudofaeces (Gilek et al. 1997). In contrast, a continuous supply of particles, and thus new adsorption sites, due to particle resuspension may extract dissolved contaminants from the water phase and deposit them on the sediment surface. Thirty-eight percent of the $\mathrm{Cd}$ and $70 \%$ of the BDE-99 in the overlying water in the $M$. affinis cores was associated with suspended 
particles. The relatively low contaminant release to the water in cores with $M$. affinis could thus be a result of contaminant scavenging by the continuous supply of particles and new adsorption sites, particularly in a closed microcosm system like the one used in this experiment.

\section{Effects of OM quality}

In the presence of macrofauna, the addition of various OM forms only had an effect on the redistribution of Cd, and only in the cores with Marenzelleria, where the burial and release of $\mathrm{Cd}$ increased when it was associated with algae compared to sediment or lignin. It was hypothesised that the input of OM with a high nutritional quality (i.e. the algae) would stimulate infaunal feeding and bioturbation activities, thereby increasing the overall redistribution of the associated contaminants. An immediate response of all 3 species to the addition of algae was observed, clearing the deposited green algal layer on the sediment surface within 1 or $2 \mathrm{~d}$. The increased burial and release of $\mathrm{Cd}$ in the algae treatment by Marenzelleria could therefore, in part, be explained by increased feeding activity, burrow ventilation and mobility of these polychaetes, increasing water movement and hence physical transport of $\mathrm{Cd}$ in the sediment and over the sediment-water interface. Enhanced bio-irrigation rates after organic enrichment have previously been reported for the polychaete Nereis diversicolor (Banta et al. 1999, Heilskov et al. 2006), as well as for Macoma balthica (Heilskov et al. 2006) and Monoporeia affinis (Karlson et al. 2007). The lack of measurable effect of OM types on the redistribution of $\mathrm{Cd}$ by $M$. balthica and $M$. affinis could perhaps be due to the experimental design, with a single sampling occasion at the end of the experiment. Karlson et al. (2007) recently showed that the initial increase in activity of $M$. affinis following a simulated spring bloom only lasted for $5 \mathrm{~d}$.

Several trace metals (e.g. $\mathrm{Cu}, \mathrm{Cd}, \mathrm{V}$ ) are readily remobilised from freshly deposited OM due to aerobic mineralisation of the OM in the oxidised sediment surface layer (Riedel et al. 1999, Audry et al. 2006). In addition to the release of free metal ions to the interstitial water during OM degradation, an increase in DOM may add to the solubilisation of metals due to DOMcomplexation (Hoss et al. 2001). Moreover, the sorption capacity is generally suggested to be lower for labile OM than for older more refractory OM. Lignins, for example, strongly adsorb many metal ions and are being developed for use as biosorbents for removing toxic metals from waste water (Mohan et al. 2006). They have a complex aromatic molecular structure, low water solubility and resistance to degradation. The higher redistribution of $\mathrm{Cd}$ in the algae treatment by Marenzelleria is thus probably the result of several cooccurring factors: a higher diagenetic release of soluble Cd from the labile algae than from lignin or sediment, a higher bioturbation activity, and the mode of bioturbation displayed by Marenzelleria (bio-irrigation).

No effect of the various types of OM on the redistribution of BDE-99 was observed. This was probably due to the highly hydrophobic and particle reactive properties of BDE-99, resulting in a very low soluble fraction and thus limited transport by Marenzelleria. An organic contaminant with a more moderate $\mathrm{K}_{\mathrm{OW}}$ and higher water solubility may have been more affected by the OM additions. For example, Dewitt et al. (1992) found increased porewater concentrations of the PAH fluoranthene in sediments amended with ground macroalgae compared to other OM types (e.g. mud), and Gunnarsson et al. (1999b) reported an increased release rate of $\mathrm{PCB}$ from unbioturbated sediments enriched with algae compared to non-enriched sediment.

\section{Implications for contaminant fate in the field}

The semi-enclosed brackish Baltic Sea is dominated by few macrofaunal species, mainly small-sized surface-deposit feeders (Bonsdorff \& Pearson 1999). Although well studied in marine and freshwater environments (Schaffner et al. 1997, Christensen et al. 2002, Thibodeaux \& Bierman 2003), few and inconclusive experimental studies have addressed the role of bioturbation on contaminant distribution in the Baltic Sea. For example, the remobilisation of metals from historically contaminated sediments by Monoporeia affinis was unexpectedly small (Sundelin \& Eriksson 2001), while the release of organic contaminants from sediments bioturbated by Marenzelleria neglecta was significant (Granberg et al. 2008). Results presented here generally suggest that bioturbation by some of the most common species in the Baltic Sea increases the retention of contaminants deposited on the sediment surface.

The spionid polychaete genus Marenzelleria was first discovered in the Baltic Sea in the 1980s. In some areas, Marenzelleria now dominates both in biomass and abundance, and there are indications of concurrent decreasing densities of several native species, among them Monoporeia affinis (Kotta \& Olafsson 2003, Perus \& Bonsdorff 2004). Despite a significant change in the community structure, ecological impacts of the invasion are still not well investigated or understood, although it has recently been suggested that the high abundance of Marenzelleria may change sediment processes in the Baltic (Kotta et al. 2006). Results presented in our study support such speculations. For 
example, a shift in the community composition of a deep, soft-bottom habitat dominated by $M$. affinis to a community dominated by Marenzelleria could significantly change the contaminant dynamics in that area, increasing the mobility of contaminants. Normal field densities of each species were used in this experiment, i.e. the density and biomass varied between treatments, for more ecologically realistic comparisons on their effect on contaminant fate in the field. However, large variations in population densities are common between areas (Perus \& Bonsdorff 2004). This variation should be taken into consideration when interpreting the results, since bioturbation intensity has been positively correlated with both size and abundance of infauna (Reible et al. 1996, Sandnes et al. 2000).

Input of labile OM can increase the mobilisation of contaminants from the sediment surface. This may be the result of a combined effect of increased animal feeding and bioturbation activity, and a high diagenetic release due to OM degradation. In the presence of bioturbators similar to the ones used in this experiment, this effect is probably strongest for metals that are predominantly mobile under oxidising conditions (e.g. $\mathrm{Cd}, \mathrm{Cu}, \mathrm{Zn}$ ), and for organic contaminants with moderate $\mathrm{K}_{\mathrm{OW}}$ and/or soluble metabolites (e.g. PAHs and lower chlorinated PCBs). However, a high load of $\mathrm{OM}$ to the sediment surface can also cause oxygen depletion and in extreme cases defaunation (Pearson \& Rosenberg 1978), leading to an opposite effect on the fate of the above mentioned contaminants due to a slower OM mineralisation, slower contaminant degradation and precipitation of metals under reducing conditions. Under normal spring-bloom conditions, the risk of contaminant mobilisation may increase. This emphasises the importance of understanding how ecological and physiochemical processes interact when assessing the fate, and ultimately the effect, of contaminants in aquatic ecosystems.

Acknowledgements. We thank M. Jansson's group at The Royal Institute of Technology (KTH) for their kind help in analysing samples for gamma activity, the staff at Askö Marine Laboratory for their assistance in the field, and Dr. F. Gilbert at Centre d' Océanologie de Marseille for valuable help and discussions on bioturbation activity. The authors appreciate very helpful comments from referees contributing to clarify and improve the original manuscript. This study was funded by grants from The Swedish Research Council FORMAS (grant no. 216-2005-1424), The Foundation for Baltic and East European Studies and the Stockholm Marine Research Centre (SMF).

\section{LITERATURE CITED}

Aller RC (1988) Benthic fauna and biogeochemical processes in marine sediments: the role of burrow structures. In: Blackburn TH, Sorenson J (eds) Nitrogen cycling in coastal marine environments. John Wiley \& Sons, Chichester, p 301-338

Aller RC, Aller JY (1998) The effect of biogenic irrigation intensity and solute exchange on diagenetic reaction rates in marine sediments. J Mar Res 56:905-936

Audry S, Blanc G, Schafer J, Chaillou G, Robert S (2006) Early diagenesis of trace metals $(\mathrm{Cd}, \mathrm{Cu}, \mathrm{Co}, \mathrm{Ni}, \mathrm{U}, \mathrm{Mo}$, and $\mathrm{V})$ in the freshwater reaches of a macrotidal estuary. Geochim Cosmochim Acta 70:2264-2282

Banta GT, Andersen O (2003) Bioturbation and the fate of sediment pollutants - experimental case studies of selected infauna species. Vie Milieu-Life Environ 53:233-248

Banta GT, Holmer M, Jensen MH, Kristensen E (1999) Effects of two polychaete worms, Nereis diversicolor and Arenicola marina, on aerobic and anaerobic decomposition in a sandy marine sediment. Aquat Microb Ecol 19:189-204

Bastrop R, Blank M (2006) Multiple invasions - a polychaete genus enters the Baltic Sea. Biol Invasions 8:1195-1200

Bogander LE (1976) Redox measurements in natural waters and sediment. In: Dybern BI, Ackefors H, Elmgren R (eds) Baltic Sea recommendations on methods for marine biological studies in the Baltic Sea. Balt Mar Biol No. 1a, p 47-47

Bonsdorff E, Pearson TH (1999) Variation in the sublittoral macrozoobenthos of the Baltic Sea along environmental gradients: a functional-group approach. Aust J Ecol 24: 312-326

Caradec S, Grossi V, Hulth S, Stora G, Gilbert F (2004) Macrofaunal reworking activities and hydrocarbon redistribution in an experimental sediment system. J Sea Res 52: 199-210

Chapman PM, Wang FY, Janssen C, Persoone G, Allen HE (1998) Ecotoxicology of metals in aquatic sediments: binding and release, bioavailability, risk assessment, and remediation. Can J Fish Aquat Sci 55:2221-2243

Christensen M, Banta GT, Andersen O (2002) Effects of the polychaetes Nereis diversicolor and Arenicola marina on the fate and distribution of pyrene in sediments. Mar Ecol Prog Ser 237:159-172

Ciarelli S, van Straalen NM, Klap VA, van Wezel AP (1999) Effects of sediment bioturbation by the estuarine amphipod Corophium volutator on fluoranthene resuspension and transfer into the mussel (Mytilus edulis). Environ Toxicol Chem 18:318-328

Ciutat A, Boudou A (2003) Bioturbation effects on cadmium and zinc transfers from a contaminated sediment and on metal bioavailability to benthic bivalves. Environ Toxicol Chem 22:1574-1581

de Wit CA (2002) An overview of brominated flame retardants in the environment. Chemosphere 46:583-624

DeWitt TH, Ozretich RJ, Swartz RC, Lamberson JO and 5 others (1992) The influence of organic-matter quality on the toxicity and partitioning of sediment-associated fluoranthene. Environ Toxicol Chem 11:197-208

DeWitt TH, Hickey CW, Morrisey DJ, Nipper MG, Roper DS, Williamson RB, Van Dam L, Williams EK (1999) Do amphipods have the same concentration-response to contaminated sediment in situ as in vitro? Environ Toxicol Chem 18:1026-1037

Di Toro DM, Mahony JD, Hansen DJ, Scott KJ, Hicks MB, Mayr SM, Redmond MS (1990) Toxicity of cadmium in sediments: the role of acid volatile sulfide. Environ Toxicol Chem 9:1487-1502

Ferro I, Van Nugteren P, Middelburg JJ, Herman PMJ, Heip CHR (2003) Effect of macrofauna, oxygen exchange and particle reworking on iron and manganese sediment biogeochemistry: a laboratory experiment. Vie Milieu-Life Environ 53:211-220 
Gilbert F, Stora G, Bertrand JC (1996) In situ bioturbation and hydrocarbon fate in an experimental contaminated Mediterranean coastal ecosystem. Chemosphere 33:1449-1458

Gilek M, Bjork M, Broman D, Kautsky N, Kautsky U, Naf C (1997) The role of the blue mussel, Mytilus edulis, in the cycling of hydrophobic organic contaminants in the Baltic proper. Ambio 26:202-209

Graf G (1992) Benthic-pelagic coupling: a benthic view. Oceanogr Mar Biol Annu Rev 30:149-190

Granberg ME, Gunnarsson JS, Hedman JE, Rosenberg $\mathrm{R}_{\imath}$ Jonsson P (2008) Bioturbation-driven release of organic contaminants from Baltic Sea sediments mediated by the invading polychaete Marenzelleria neglecta. Environ Sci Technol 42:1058-1065

Gunnarsson JS, Granberg ME, Nilsson HC, Rosenberg R, Hellman B (1999a) Influence of sediment-organic matter quality on growth and polychlorobiphenyl bioavailability in echinodermata (Amphiura filiformis). Environ Toxicol Chem 18:1534-1543

Gunnarsson JS, Hollertz K, Rosenberg R (1999b) Effects of organic enrichment and burrowing activity of the polychaete Nereis diversicolor on the fate of tetrachlorobiphenyl in marine sediments. Environ Toxicol Chem 18:1149-1156

Hedges JI, Stern JH (1983) Carbon and nitrogen determinations of carbonate-containing solids. Limnol Oceanogr 29: $657-663$

Heilskov AC, Alperin M, Holmer M (2006) Benthic fauna bioirrigation effects on nutrient regeneration in fish farm sediments. J Exp Mar Biol Ecol 339:204-225

HELCOM (2003) The Baltic marine environment. Helsinki Commission

Hoss S, Henschel T, Haitzer M, Traunspurger W, Steinberg CEW (2001) Toxicity of cadmium to Caenorhabditis elegans (Nematoda) in whole sediment and pore water - the ambiguous role of organic matter. Environ Toxicol Chem 20:2794-2801

Jumars PA, Wheatcroft RA (1989) Responses of benthos to changing food quality and quantity, with a focus on deposit feeding and bioturbation. In: Berger $\mathrm{WH}_{\text {, Sme- }}$ tacek VS, Wefer G (eds) Productivity in the ocean: present and past. John Wiley \& Sons, New York, p 235-253

Karlson K, Hulth S, Ringdahl K, Rosenberg R (2005) Experimental recolonisation of Baltic Sea reduced sediments: survival of benthic macrofauna and effects on nutrient cycling. Mar Ecol Prog Ser 294:35-49

Karlson K, Hulth S, Rosenberg R (2007) Density of Monoporeia affinis and biogeochemistry in Baltic Sea sediments. J Exp Mar Biol Ecol 344:123-135

Kotta J, Olafsson E (2003) Competition for food between the introduced polychaete Marenzelleria viridis (Verrill) and the native amphipod Monoporeia affinis Lindstrom in the Baltic Sea. J Sea Res 50:27-35

Kotta J, Kotta I, Simm M, Lankov A, Lauringson V, Pollumae A, Ojaveer H (2006) Ecological consequences of biological invasions: three invertebrate case studies in the northeastern Baltic Sea. Helgol Mar Res 60:106-112

Kristensen E, Andersen FO, Blackburn TH (1992) Effects of benthic macrofauna and temperature on degradation of macroalgal detritus - the fate of organic carbon. Limnol Oceanogr 37:1404-1419

Larsson U, Hobro R, Wulff F (1986) Dynamics of a phytoplankton spring bloom in a coastal area of the northern Baltic Proper. Contrib Askö Lab Univ Stockholm Sweden 30:1-32

Lin JD, Hines AH (1994) Effects of suspended food availability on the feeding mode and burial depth of the Baltic clam, Macoma balthica. Oikos 69:28-36
Lueking AD, Huang WL, Soderstrom-Schwarz S, Kim MS, Weber WJ (2000) Relationship of soil organic matter characteristics to organic contaminant sequestration and bioavailability. J Environ Qual 29:317-323

Magnusson K, Agrenius S, Ekelund R (2003) Distribution of a tetrabrominated diphenyl ether and its metabolites in softbottom sediment and macrofauna species. Mar Ecol Prog Ser 255:155-170

Maire O, Duchene JC, Rosenberg R, de Mendonca JB, Gremare A (2006) Effects of food availability on sediment reworking in Abra ovata and A. nitida. Mar Ecol Prog Ser 319:135-153

Mermillod-Blondin F, Francois-Carcaillet F, Rosenberg R (2005) Biodiversity of benthic invertebrates and organic matter processing in shallow marine sediments: an experimental study. J Exp Mar Biol Ecol 315:187-209

Michaud E, Desrosiers G, Mermillod-Blondin F, Sundby B, Stora G (2005) The functional group approach to bioturbation: the effects of biodiffusers and gallery-diffusers of the Macoma balthica community on sediment oxygen uptake. J Exp Mar Biol Ecol 326:77-88

Mohan D, Pittman CU, Steele PH (2006) Single, binary and multi-component adsorption of copper and cadmium from aqueous solutions on Kraft lignin - a biosorbent. J Coll Interface Sci 297:489-504

Pearson HT, Rosenberg R (1978) Macrobenthic succession in relation to organic enrichment and pollution of the marine environment. Oceanogr Mar Biol Annu Rev 16: 229-311

Perus J, Bonsdorff E (2004) Long-term changes in macrozoobenthos in the Aland archipelago, northern Baltic Sea. J Sea Res 52:45-56

Petersen K, Kristensen E, Bjerregaard P (1998) Influence of bioturbating animals on flux of cadmium into estuarine sediment. Mar Environ Res 45:403-415

Peterson GS, Ankley GT, Leonard EN (1996) Effect of bioturbation on metal-sulfide oxidation in surficial freshwater sediments. Environ Toxicol Chem 15:2147-2155

Reible DD, Popov V, Valsaraj KT, Thibodeaux LJ and others (1996) Contaminant fluxes from sediment due to tubificid oligochaete bioturbation. Water Res 30:704-714

Riedel GF, Sanders JG, Osman RW (1999) Biogeochemical control on the flux of trace elements from estuarine sediments: effects of seasonal and short-term hypoxia. Mar Environ Res 47:349-372

Riisgard HU, Larsen PS (2005) Water pumping and analysis of flow in burrowing zoobenthos: an overview. Aquat Ecol 39:237-258

Sandnes J, Forbes T, Hansen R, Sandnes B, Rygg B (2000) Bioturbation and irrigation in natural sediments, described by animal-community parameters. Mar Ecol Prog Ser 197: 169-179

Schaffner LC, Dickhut RM, Mitra S, Lay PW, Brouwer-Riel C (1997) Effects of physical chemistry and bioturbation by estuarine macrofauna on the transport of hydrophobic organic contaminants in the benthos. Environ Sci Technol 31:3120-3125

Schwarzenbach RP, Gschwend PM, Imboden DM (2003) Environmental organic chemistry, 2nd edn. John Wiley \& Sons, New York

Selck H, Granberg ME, Forbes VE (2005) Impact of sediment organic matter quality on the fate and effects of fluoranthene in the infaunal brittle star Amphiura filiformis. Mar Environ Res 59:19-45

Smith CR, Pope RH, Demaster DJ, Magaard L (1993) Agedependent mixing of deep-sea sediments. Geochim Cosmochim Acta 57:1473-1488 
Sundelin B, Eriksson AK (2001) Mobility and bioavailability of trace metals in sulfidic coastal sediments. Environ Toxicol Chem 20:748-756

Thibodeaux LJ, Bierman VJ (2003) The bioturbation-driven chemical release process. Environ Sci Technol 37:252A-258A

Tittlemier SA, Halldorson T, Stern GA, Tomy GT (2002) Vapor pressures, aqueous solubilities, and Henry's law constants of some brominated flame retardants. Environ Toxicol Chem 21:1804-1810

Voyer RA, Modica G (1990) Influence of salinity and temper-

Editorial responsibility: Lisa Levin,

La Jolla, California, USA ature on acute toxicity of cadmium to Mysidopsis bahia Molenock. Arch Environ Contam Toxicol 19:124-131

Wollenberger L, Dinan L, Breitholtz M (2005) Brominated flame retardants: activities in a crustacean development test and in an ecdysteroid screening assay. Environ Toxicol Chem 24:400-407

Zettler ML, Bick A, Bochert R (1995) Distribution and population-dynamics of Marenzelleria viridis (Polychaeta, Spionidae) in a coastal water of the southern Baltic. Arch Fish Mar Res 42:209-224

Submitted: December 21, 2006; Accepted: August 22, 2007 Proofs received from author(s): February 1, 2008 